\title{
A descriptive study to assess the prevalence of overweight and obesity by calculating BMI (Body Mass Index) among women at selected community area of Bhopal, Madhya Pradesh, India
}

\author{
Pakhide V. ${ }^{{ }^{*}}$ \\ DOI: https://doi.org/10.17511/ijphr.2019.i6.01
}

1* Vandana Pakhide, Assistant Professor, Pragyan College of Nursing, Bhopal, Madhya Pradesh, India.

\begin{abstract}
Background: Obesity and overweight have become a global epidemic now. Overweight and obesity are the fifth leading risks of death of adults globally every year. Obesity is defined as abnormal or excessive fat accumulation that may impair health. Obesity can occur at any age and generally increased with age. Women generally have higher rate of obesity than men. As the most developing nation, India is struggling to eradicate the problem of under nutrition and anaemia. Meanwhile the country already witnessed the overweight and obesity problem. India has more than 30 million obese people, and the number is increasing rapidly. The main aim of this study to assess the prevalence of overweight and obesity among women by calculating BMI (Body Mass Index). Methods: A descriptive study design was used to assess the prevalence of overweight and obesity by calculating BMI among women at selected community area of Bhopal. Sample size 100 was selected by using convenient sampling technique and who met the inclusive criteria. Results: out of 100 samples 30(30\%) women are underweight, 15(15\%) women's having normal body weight, $37(37 \%)$ women overweight and 18(18\%) are obese. Conclusion: Prevalence of overweight was high as compared to obesity in community area; the history of any other illness and history of any other medications was strongly associated with obesity. Obesity is the main cause of chronic illness and risk of being obese is increasing in women, so this study will help to find out the prevalence and contributing factors about obesity so that problem will be addressed and making general public aware to reduce the risk factors.
\end{abstract}

Keywords: Prevalence, Overweight, Obesity, BMI

Corresponding Author

Vandana Pakhide, Assistant Professor, Pragyan College of Nursing, Bhopal, Madhya Pradesh, India. Email: pakidevandana@yahoo.in
How to Cite this Article

Pakhide V. A descriptive study to assess the prevalence of overweight and obesity by calculating BMI (Body Mass Index) among women at selected community area of Bhopal, Madhya Pradesh, India. Public Health Rev Int J Public Health Res. 2020;6(6):214-218.

Available From

https://publichealth.medresearch.in/index.php/ijphr/ article/view/123
To Browse

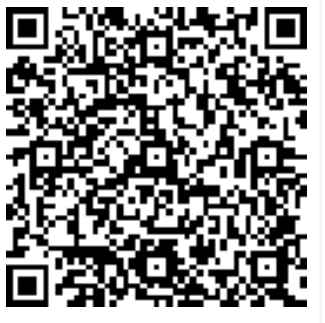

Manuscript Received 2019-08-17

Conflict of Interest No

Review Round 1
2019-11-04
Funding
Nil

Review Round 2
2019-11-12
Ethical Approval
Yes

Accepted 2019-11-28

(c) 2020 by Vandana Pakhide and Published by Siddharth Health Research and Social Welfare Society. This is an Open Access article licensed under a Creative Commons Attribution 4.0 International License https://creativecommons.org/licenses/by/4.0/ unported [CC BY 4.0]. 


\section{Introduction}

Obesity can occur at any age and generally increased with age. Women generally have higher rate of obesity than men, although men may have higher rate of overweight in the Framingham, USA study, men were found to gain most weight between the ages of 29 and 35 years, while women gain most between 45 and 49 years of age [1].

In developing and developed countries, obesity has reached epidemic proportions. In India obesity is reaching epidemic proportions, with morbid obesity affecting $5 \%$ of the population. Indians are genetically predisposed to fat accumulation particularly around the waist. According to national family health survey data the prevalence of overweight and obesity is highest in north India, with percentage being high as $30 \%$ in males and $37.5 \%$ in females, whereas the states in North-east India have a comparatively lower prevalence of 5$8 \%$ in males and $5 \%$ to $9 \%$ in females, national average being $8 \%$. According to the world health organization (WHO) there will be about 2.3 billion overweight people aged 15 years and above and over 700 million obese people worldwide in 2015. Overweight and obesity are the fifth leading risk of death, resulting in around 2.8 million death of adults globally every year [2].

Risk factors such as age, gender, genetic factors, physical inactivity, eating habits, endocrine factors, socio economic status and drugs play a role in increasing obesity. Obesity can occur at any age and generally increased with age. Infants with excessive weight gain have all increased incidence of obesity in later life. There are many reasons why women have more body fat than men.

$\mathrm{Ne}$ is biological. Body fat content is $25 \%$ for women at normal size compared to $15 \%$ for men. All other things being equal, such as age and exercise levels, women require fewer calories per pound of body weight daily than do men. Female hormones make it easier to convert fat into food. Women more often do the cooking in the households. Finally, in fatprone women, birth control pills cause the body to produce increased amounts of fat and water.

Estrogen alone will cause increased deposition of fat. Sedentary lifestyle particularly sedentary occupation and inactive recreation such as watching television promote of mortality and morbidity related to overweight and obesity, obesity is associated with higher socio-economic groups.
Use of certain drug e.g. corticosteroids, contraceptive, insulin, Beta adrenergic blocker, etc. can promote weight gain [3-6].

BMI- Body mass index (BMI) is a simple index of weight-for-height that is commonly used to classify overweight and obesity in adults.

The formula: weight in kilograms is divided by height in meters squared [weight $(\mathrm{kg}) /$ height $(\mathrm{m} 2)$ ]. In adults, healthy weight is $18-25 \mathrm{BMI}$, overweight is 25-29 BMI, obese is a BMI of 30 or greater and morbid obese is a BMI of $>40$.

Obesity and overweight have become a global epidemic now. According to WHO definition Obesity is BMI greater than or equal to 25 is overweight and BMI greater than or equal to 30 is obesity. Raised BMI is a major risk factor for non-communicable diseases such as:

- Cardiovascular diseases (mainly heart disease and stroke), which were the leading cause of death in 2012;

- Diabetes

- Musculoskeletal disorders (especially osteoarthritis - a highly disabling degenerative disease of the joints);

- Some cancers (including endometrial, breast, ovarian, prostate, liver, gallbladder, kidney, and colon) [8].

\section{Problem Statement}

"A study to assess the prevalence of overweight and obesity by calculating BMI (Body Mass Index) among women at selected community area of Bhopal (M.P.)."

\section{Objectives}

01 . Assess the prevalence of overweight and obesity by calculating BMI among women.

02. Associate BMI finding with their selected demographical variables and clinical variables among women.

\section{Research Methodology}

Study design: In this study a simple descriptive approach was used to assess the prevalence of overweight and obesity among women's by calculating BMI.

Setting: This study is being conducted in selected rural community Gondipura at Bhopal. 
Duration: May, 2018

Sample size: 100 selected through convenient sampling technique

Ethical Approval: Study was approved by the Administrative and Ethical committee

\section{Inclusion criteria}

- Women who were interested to participate in the study.

- Women who were available at the time of data collection.

\section{Exclusion criteria}

- Women who are not interested to participate and not available at the time of data collection.

Procedure of data collection- A self-preparing data collection technique by using paper and pencil method was used in order to obtain data, measured physical characteristics such as height and weight, The study samples were assured of confidentially of their responses.

Based on the objectives of the study performed data collection procedure, measured the height and weight, help to assess the prevalence of overweight and obesity by calculating BMI

\section{Scoring criteria}

Table-1: BMI range the scoring criteria:

\begin{tabular}{|l|l|l|}
\hline \multicolumn{1}{|c|}{ S. No. } & \multicolumn{1}{|c|}{ Category } & \multicolumn{1}{c|}{ BMI Range $(\mathrm{kg} / \mathrm{m} 2)$} \\
\hline 1. & Underweight & $16.0-18.5$ \\
\hline 2. & Normal & $18.5-25$ \\
\hline 3. & Overweight & $25-30$ \\
\hline 4. & Obese & Over30 \\
\hline
\end{tabular}

Data analysis: The data obtained from 100 respondents was analyzed by using descriptive and inferential statistics follows:

- A master data sheet was prepared and compiled demographic data, containing selected sample characteristics and analyzed using frequency and percentage distribution.

- Chi square test was used to find out the association of findings with their selected demographical variables and clinical variables among women.

\section{Results}

Result in terms of Objectives of the study:

1. Assess the prevalence of overweight and obesity by calculating BMI among women.
Out of 100 samples 30(30\%) women's are underweight, 15 (15\%) women's having normal body weight, 37 (37\%) women overweight and 18 $(18 \%)$ are obese.

Table -2: Prevalence of overweight and obesity by calculating BMI

\begin{tabular}{|l|l|l|l|c|}
\hline Sample size & Under weight & Normal & Overweight & Obese \\
\hline 100 & $30(30 \%)$ & $15(15 \%)$ & $37(37 \%)$ & $18(18 \%)$ \\
\hline
\end{tabular}

1. Associate BMI finding with their selected demographical variables and clinical variables among women.

Demographic variables age, religion, education, occupation and socio-economic status not associated with obesity,

Table -3: Association of BMI finding with selected clinical variables

\begin{tabular}{|l|l|l|l|l|l|l|l|}
\hline $\begin{array}{r}\text { S. } \\
\text { No. }\end{array}$ & \multicolumn{1}{|c|}{$\begin{array}{c}\text { Clinical } \\
\text { variables }\end{array}$} & $\begin{array}{c}\text { Under } \\
\text { weight }\end{array}$ & Normal & Overweight & Obese df & x2 \\
\hline 1. & \multicolumn{7}{|c|}{ History of any other illness } \\
\hline a. & Yes & 10 & 10 & 24 & 08 & 3 & $\begin{array}{l}8.25 \\
*\end{array}$ \\
\hline b. & No & 20 & 05 & 13 & 10 & $*$ \\
\hline 2. & \multicolumn{7}{|c|}{ History of any other medication } \\
\hline a. & Yes & 10 & 15 & 30 & 09 & 3 & 26.5 \\
\hline b. & No & 20 & 0 & 07 & 09 & $*$ \\
\hline
\end{tabular}

*Significant at 0.05 level of significance

Clinical variables such as family history of obesity, history of any other illness, history of any other medication, history of eating disorder, history of any other exercise schedule and history of any previous surgery.

The analysis revealed that the history of any other illness and history of any other medication was strongly associated with obesity.

\section{Discussion}

Interms of demographic variables age, religion, education, occupation and socio-economic status not associated with obesity, clinical variables such as family history of obesity, history of any other illness, history of any other medication, history of eating disorder, history of any other exercise schedule and history of any previous surgery.

The analysis revealed that the history of any other illness and history of any other medication was strongly associated with obesity. Findings of the study are consistent with the study conducted by J. Gouda, R.K. Prusty. Women of different age-groups across the economic strata of households; 
It is observed that women at later age (35+ years) are more overweight or obese than the reference group in 15-24 years. The prevalence of overweight and obesity is higher among urban women than their rural counterparts in India.

More than $23 \%$ of women in the urban area are either overweight or obese compared to only $7 \%$ of women in rural areas. More than one-sixth of women in urban area are overweight, and around $6 \%$ of women are obese. The problem is more acute among the non-poor than the poor in urban India [7-10].

Prevalence of overweight and obesity observed in the study by Yarlini Balarajan, Eduardo Villamor Using nationally representative data from 8 Demographic and Health Surveys conducted in Bangladesh $(n=19,211)$, Nepal $(n=19,354)$, and India $(n=161,755)$, we examined the change in the prevalence rates of overweight-obesity (BMI $\geq 25$ $\mathrm{kg} / \mathrm{m} 2$ ) and underweight (BMI $<18.5 \mathrm{~kg} / \mathrm{m} 2$ ) over a recent 7- to 10-y period among women aged 15-49 years.

The prevalence of overweight-obesity increased substantially in all countries. Comparing the first to the latest survey in Bangladesh, the prevalence of overweight-obesity increased from 2.7 to $8.9 \%$ [age and parity-adjusted prevalence ratio (PR): 2.42; $95 \%$ CI: $1.88,3.13$ ]; in Nepal, from 1.6 to $10.1 \%$ [adjusted PR: $4.18 ; 95 \% \mathrm{CI}: 3.00,5.83$ ]; and in India, from 10.6 to $14.8 \%$ [adjusted PR: $1.28 ; 95 \%$ CI: $1.20,1.36]$. These increases were observed in both rural and urban areas and were greater in rural areas [11].

According to the National Family Health Survey (NFHS), the percentage of ever-married women aged 15-49 years who are overweight or obese increased from $11 \%$ in NFHS- 2 to $15 \%$ in NFHS-3. Under nutrition is more prevalent in rural areas, whereas overweight and obesity are more than three times higher in urban areas.

This may be due to lesser physical activity in the urban areas. The percentage of women who are overweight or obese is highest in Punjab (30\%), followed by Kerala (28\%) and Delhi $(26 \%)$, all of which are relatively richer states.

Kalra S, Unnikrishnan A. G. concluded result that increasing trend in obesity among the urban and also in the rural population ( $>20$ years) in Chennai, South India. In a decade, the prevalence of obesity had increased by 1.7 -fold in the city.
Obesity rates were higher among women, as reported from many other countries. The prevalence of overweight was lower among the urbanizing rural population, than in the urban areas [12].

\section{Limitations}

The limitations of the study are-

- The study was limited to only women of rural area.

- It was limited to one month of data collection.

\section{Conclusion}

Prevalence of overweight was high as compared to obesity in community area; the history of any other illness and history of any other medications was strongly associated with obesity. Obesity is the main cause of chronic illness and risk of being obese is increasing in women, so this study will help to find out the prevalence and contributing factors about overweight and obesity so that problem will be addressed and making general public aware to reduce the risk factors.

\section{What the study adds to the existing knowledge}

Obesity can occur at any age and generally increased with age. Risk factors such as age, gender, genetic factors, physical inactivity, eating habits, endocrine factors, socio economic status and drugs play a role in increasing overweight and obesity. This study is supporting the fact that the prevalence of overweight and obesity is strongly related to history of medication and other illness.

\section{Recommendations}

- A similar study can be conducted with large sample with different setting.

- A comparative study can be conducted between urban and rural community.

- A similar study can also be done in higher economic group of women.

- A similar study can be replicated on a sample with different demographic characteristics.

\section{Reference}

01. Amudha P, Lorna A. Obesity among Young Adults in Developing Countries- A Systematic Overview. Curr Obes Rep. 2016;5;2-13.

doi: $\quad 10.1007 / \mathrm{s} 13679-016-0187-x \quad$ [Crossref] 
02. World Health Organization. Washington DCObesity and overweight. World Health Organization. 2013.

Available at: [Article] [Crossref]

03. Chan RSM, Woo J. Prevention of Overweight and Obesity- How Effective is the Current Public Health Approach. Int J Environ Res Public Health. 2010;7(3)765-783.

doi: $10.3390 /$ ijerph7030765 [Crossref]

04. Anand S, Razak F, Davis AD, Jacobs R, Vuksan $V$, Teo $K$ et al. Socio disadvantage and cardiovascular disease- Development of an index and analysis of age, sex and ethnicity effects. Int J Epidemiol. 2006;35(5)1239-1245. doi: $10.1093 /$ ije/dyl163 [Crossref]

05. Chizuru N, Ricardo U, Shiriki K, Prakash S. Joint WHO/FAO expert consultation, Diet, nutrition and the prevention of chronic disease. GenevaWorld Health Organization, Public Health Nutri. 2003; 7(1A)245-250.

doi: $10.1079 /$ PHN2003592 [Crossref]

06. Nishida C. Appropriate body mass index for Asian population and its implications for policy and intervention strategies. Lancet. 2004;363(9403)157-163.

doi: [Article] [Crossref]
07. Gouda J, Prusty RK. Overweight and Obesity among Women by Economic Stratum in Urban India. J Health Popul Nutr. 2014;32(1)79-88.

[Crossref]

08. Lewis, L. Sharon \& Heitkemper Mclean Margart. Medical Surgical Nursing. India; Thomson Press limited.

2009 [Crossref]

09. Dua S, Bhuker M, Sharma P, Dhall M, Kapoor S. Body Mass Index Relates to Blood Pressure Among Adults. N Am J Med Sci. 2014;6(2)8995.

doi: $10.4103 / 1947-2714.127751$ [Crossref]

10. Medicine Net. Fat differences in men vs women article, Why are women the Fatter Sex?. 2002. [Crossref]

11. Yarlini B, Eduardo V. Nationally Representative Surveys Show Recent Increases in the Prevalence of Overweight and Obesity among Women of Reproductive Age in Bangladesh, Nepal, and India. J Nutri. 2009;139(11)21392144.

doi: jn.109.112029 [Article] [Crossref]

12. Kalra S, Unnikrishnan A G. Obesity in India- The weight of the nation. J Med Nutr Nutraceut. $2012 ; 1$ (1)37-41.

doi: $10.4103 / 2278-019 \times .94634$ [Crossref] 